\title{
UNIVALENCY OF A NONLINEAR INTEGRAL OPERATOR OF ANALYTIC FUNCTIONS
}

\section{B. A. FRASIN}

Abstract. In this paper, we obtain new univalence conditions for the nonlinear integral operator $F_{\alpha}(p)(z)=\left[\alpha \int_{0}^{z} u^{\alpha-1} \exp \left(\int_{0}^{u} \frac{\beta(p(t)-1)}{t} d t\right) d u\right]^{\frac{1}{\alpha}}$ where $p(z)$ is analytic function in the open unit disk and satisfies $p(0)=1, \alpha \in \mathbb{C}$ with $\operatorname{Re}(\alpha)>0$ and $\beta \in \mathbb{C}^{*}=\mathbb{C} \backslash\{0\}$. The numbers of known or new univalence conditions are shown to follow upon specializing the parameters involved in our main results.

Mathematics subject classification (2010): 30C45.

Keywords and phrases: Analytic and univalent functions, integral operator.

\section{REFERENCES}

[1] A. A. ATtiYA, Nonlinear operator and the sufficient conditions of univalence with applications, Journal of Mathematical Inequalities (In press).

[2] Á. BARICZ AND B. A. Frasin, Univalence of integral operators involving Bessel functions, Applied Mathematics Letters, Volume 23, Issue 4, 2010, Pages 371-376.

[3] D. BlezU And R. N. Pascu, Univalence criteria for integral operators, Glasnik Math. 36 (56) (2001), 241-245.

[4] D. BREAZ AND N. BREAZ, Univalence conditions for certain integral operators, Studia Universitatis Babes-Bolyai, Mathematica, Vol. XLVII No. 2 (2002), 9-15.

[5] D. BREAZ AND V. PESCAR, Univalence conditions for some general integral operators, Banach J. Math. Anal. (1) 2 (2008), 53-58.

[6] S. BULUT, Univalence preserving integral operators defined by generalized Al-Oboudi differential operators, An. Şt. Univ. Ovidius Constanţa, 17 (1), 2009, 37-50.

[7] B. A. Frasin, Univalence of two general integral operator, Filomat, Vol. 23, Number 3, (2009), 223-229.

[8] B. A. FRASIn, Order of convexity and univalency of general integral operator, Journal of the Franklin Institute, Volume 348, Issue 6, 2011, 1013-1019.

[9] B. A. Frasin, New general integral operator, Computers and Mathematics with Applications, 62 (2011) 4272-4276.

[10] B. A. Frasin, M. Darus AND M. ARIF, Convexity and univalency of general integral operator, Proc. Jangjeon Math. Soc. 16 (2013), No. 4. pp. 465-437.

[11] A. W. Goodman, Univalent Functions, Vol. 1, Mariner, Tampa, Florida (1983).

[12] G. I. ORos, G. OROS AND D. BREAZ, Sufficient conditions for univalence of an integral operator, J. Ineq. Appl., Vol. 2008, Article ID 127645, 7 pages.

[13] N. N. PASCU, On a univalence criterion, II, in: Itinerant Seminar on Functional Equations, Approximation and Convexity (Cluj-Napoca, 1985), pp. 153-154, Preprint 86-6, Univ. Babes-Bolyai, Cluj-Napoca, 1985.

[14] V. PESCAR, Univalence conditions for certain integral operators, Journal of Inequalities in Pure and Applied Mathematics, Volume 7, Issue 4, Article 147.

[15] V. PESCAR, The univalence and the convexity properties for a new integral operator, Stud. Univ. Babeş-Bolyai Math. 56 (2011), No. 4, 65-69. 
[16] V. Pescar, Simple sufficient conditions for univalence, Stud. Univ. Babeş-Bolyai Math.Volume XLIX, Number 2, June 2004.

[17] Z. ZHONGZHU AND S. OWA, Convolution properties of a class of bounded analytic functions, Bulletin of The Australian Mathematical Society, Volume 45, (1992), 9-23. 